Did the Devil Make Them Do It?

The Effects of Religion in Public Goods and Trust Games ${ }^{*}$

\author{
Lisa R. Anderson \\ College of William and Mary \\ Jennifer M. Mellor \\ College of William and Mary \\ Jeffrey Milyo \\ University of Missouri
}

College of William and Mary

Department of Economics

Working Paper Number 20

Original version: September 2007

Current version: August 2008

\footnotetext{
* The authors are grateful for research support from the National Science Foundation (SES-0094800) and the Schroeder Center for Health Care Policy at the Thomas Jefferson Program in Public Policy at the College of William and Mary.
} 
COLLEGE OF WILLIAM AND MARY

DEPARTMENT OF ECONOMICS

WORKING PAPER \#20

August 2008

\title{
Did the Devil Make Them Do It? The Effects of Religion in Public Goods and Trust Games
}

\begin{abstract}
Observational studies frequently support the popular belief that religion is associated with more other-regarding behavior; however, such studies are well known to be susceptible to the confounding effects of unobserved determinants of cooperation and trust. We test whether religious affiliation and participation in religious services are associated with behavior in public goods and trust games. Contrary to popular wisdom, religious affiliation is unrelated to individual behavior. However, we do find some weak evidence that among subjects attending religious services, increased participation is associated with behavior in both public goods and trust games.
\end{abstract}

JEL Codes: C9, H4, Z1

Keywords: Public goods, experiments, religion, social capital and trust

Lisa R. Anderson

Department of Economics

College of William and Mary

Williamsburg, VA 23187

lrande@wm.edu
Jennifer M. Mellor

Department of Economics

College of William and Mary

Williamsburg, VA 23187

jmmell@wm.edu
Jeffrey Milyo

Department of Economics

Truman School of Public Affairs University of Missouri milyoj@missouri.edu 
“...God loves a cheerful giver.” - 2 Corinthians 9:7 (New International Version)

\section{Introduction}

Social scientists have long considered religion to be an important determinant of individual behavior and economic outcomes (e.g., Weber 1930). For example, at the individual level, religious adherence is associated with improved mental and physical health, marital stability, reduced incidences of criminal and delinquent activity, and lower rates of alcohol and drug abuse (Iannacone 1998). Looking across countries, Barro and McCleary (2003) find that the prevalence of certain religions and religious beliefs (e.g., the afterlife) within a country is related to economic growth. In short, religion and religiosity are associated with a variety of positive individual and social indicators. But why is this so?

One explanation for this empirical regularity is that religion may be a key component of social capital (Putnam 2000). ${ }^{1}$ For example, anthropologists have argued collective rituals may promote cooperation and cohesiveness (e.g., Ruffle and Sosis 2007); further, in a multinational survey, Guiso et al. (2003) find that religious affiliation and participation are associated with attitudes that are more favorable toward cooperation. In addition, survey evidence from the U.S. demonstrates that religious participation is strongly correlated with both charitable giving and volunteering (Putnam 2000, and Brooks 2003 and 2005). Of course, the existence of an association between religious adherence and increased cooperative behavior is not entirely

${ }^{1}$ Social capital has in turn linked to all manner of salutary outcomes, from greater economic growth to reduced political corruption, and from reduced mortality rates and to decreased abdominal weight gain; for a review and discussion of the (perhaps overhyped) consequences of social capital, see Mellor and Milyo (2005). 
surprising, given that all major religions exhort their followers (to some degree or another) to show compassion and generosity toward others. ${ }^{2}$ In this sense, religious faith may be considered a source of "warm glow” feelings or "social preferences” that induces individuals to engage in unselfish but socially beneficial behavior (Andreoni 1993, Fehr and Fischbacher 2002 and Charness and Rabin 2002). In fact, Orbell et al. (1992) confirm what they term a "folk sociology” belief that religious individuals are in general more cooperative by surveying human subject participants in a prisoners' dilemma experiment; they report a widespread belief among all subjects that religious partners would be more likely to cooperate in the prisoners' dilemma experiment.

It is tempting to infer from this empirical literature that religious individuals have more other-regarding preferences; however, Iannaccone (1998) cautions these observational studies may suffer from omitted variable or selection biases that generate spurious associations between religion and cooperation. For example, consider recent studies of survey data by Brooks (2003) and Schwadel (2005) which demonstrate that both religious affiliation and the intensity of religious participation are associated with increased voluntary contributions to charitable causes, even after controlling for income and other demographic attributes. ${ }^{3}$ Such evidence does not necessarily indicate that religious individuals have systematically different preferences toward

${ }^{2}$ Eckel and Grossman (2004) elaborate on this point; for a contemporary example of such exhortations, see Wallis (2005), who argues that Christian values should lead the faithful to support generous entitlements and redistributive policies.

${ }^{3}$ Although this same survey evidence also suggests that religious adherents (especially Protestants) give less to secular causes; consistent with this, Eckel and Grossman (2003 and 2005) find that religious and nonreligious participants in laboratory experiments do not behave differently when given the opportunity to make charitable contributions to secular causes. 
giving than non-religious individuals. Instead, it may simply be the case that some people find themselves in social environments that are more rewarding of or conducive to other-directed behavior, which induces them to give more of both their money (to charity) and their time (to religious participation). Therefore, it is possible that religious people do not have different preferences so much as they have different circumstances. In that case, unobservable differences in social environment or circumstances confound the association between religion and charitable giving.

Of course, it is by no means self-evident that religion and religiosity should have only positive consequences for social interactions. First, and perhaps most obviously, religious differences within and across societies have historically been the source of much discord. ${ }^{4}$ Second, some surveys demonstrate that religious adherence is also associated with racist, sexist, and vengeful attitudes (Guiso et al. 2003 and Greer et al. 2005). Finally, survey evidence on religion and generalized social trust is more mixed than that for giving. While raw correlations suggest that religious adherents in the U.S. are much more trusting than others, ${ }^{5}$ Welch et al. (2004) find the opposite after controlling for income, education and other demographic characteristics. Also, some authors have argued that Catholicism in particular may reduce social

${ }^{4}$ In addition, several recent studies find that population heterogeneity in ethnicity, income or race is associated with less support for public good provision (Alesina et al. 1999), reduced trust in others (Alesina and La Ferrara 2002) and lower rates of voluntary participation in membership organizations (Alesina and La Ferrara 2000). Although none of these studies tests the consequences of religious heterogeneity, it is not unreasonable to conjecture that religious differences may well have similar effects as other sources of population heterogeneity.

${ }^{5}$ Our calculations from the combined 1972-2002 General Social Survey indicate that individuals who self-identify some religious affiliation (versus none) are $66 \%$ more likely to agree that "most people can be trusted" $(p<.01)$; these survey-based definitions of both "religious affiliation" and "social trust" are commonplace in the literature. 
trust (La Porte et al. 1997, Inglehart 1999, and Putnam 1993). On the other hand, Guiso et al. (2003) find that religious affiliation and participation among all Christians is associated with increased generalized social trust (albeit more so for Protestants than Catholics). ${ }^{6}$

Aside from these caveats, it is not inconceivable that religious individuals are indeed “different” in their preferences or beliefs in others in a way that makes them more cooperative, generous or trusting. First, it may be that people who are "hard-wired” with more otherregarding preferences are more likely to join religious groups; or exposure to religious teaching may serve to remind and train people to be more other-regarding. Finally, a sincere belief in the after-life may well fundamentally alter how religious individuals perceive the payoffs to social interactions.

Putting all of this into the context of an indefinitely repeated prisoners' dilemma, we seek to answer whether the religious individuals cooperate or trust more than others when the "social environment” is controlled across religious and non-religious individuals. The answer to this question speaks to whether religion alters the way in which people perceive the benefits and costs of social interactions, as opposed to religious people either finding themselves or sorting themselves into circumstances that are more conducive to cooperation and trust. To answer this question, we control the "social environment” of religious and non-religious people by means of human-subject experiments.

In adopting this approach to investigate whether religion influences behavior we join a limited but growing experimental literature on the behavioral consequences of religion (Eckel

${ }^{6}$ Also, see Goldin and Katz (1999) and Glaeser et al. (2000) on the association between Lutheranism and trust, as well as Arrunda (2004) on differences in trust between Catholics and Protestants. 
and Grossman 2003, 2004; Ruffle and Sosis 2007; and Johansson-Stenman et al 2005).

Specifically, we examine whether religious affiliation and participation are associated with individual actions in two familiar experimental settings: a public goods game and a bilateral trust game. In the first set of experiments, we test whether religious adherents are more likely to contribute to a group account when such actions are contrary to self-interest. In the latter set of experiments, we test whether religious adherents choose to trust strangers or to behave in a trustworthy fashion, despite monetary incentives to the contrary.

In the next section, we review the nascent literature on the effects of religion and religiosity in experiments. We then describe our experimental and survey design, and present our findings. We conclude with a discussion of these findings and suggestions for future research.

\section{Religion in Laboratory Experiments}

Several investigators have examined the effects of culture, or even social capital, on individual behavior in laboratory experiments (e.g., Oosterbeek et al. 2004, and Anderson, Mellor and Milyo 2004), but relatively little attention has been paid to religion as a determinant of subjects' behavior. In fact, only four previous studies (all using non-American subjects) have examined the effect of religion in either a canonical public goods game or trust game; ${ }^{7}$ we review each of these below.

Fehr et al. (2003) examines how a wide range of socio-demographic characteristics among German experimental subjects relates to behavior in a classic bilateral trust game; in

${ }^{7}$ The classic public goods game experiment is described in Marwell and Ames (1979), while the "investment" experiment described in Berg et al.. (1995) has become the standard model for bilateral trust games. 
particular, they observe that Catholics are much more trusting in these experiments. However, religion is not the focus of their study, so the authors do not explore further the effects of attendance at services. Tan and Vogel (forthcoming) also study German subjects in trust games, where the "trustors" (i.e., first-movers) are provided with information on the religiosity of the “trustee’ (i.e., second movers). Interestingly, they find that amounts sent by trustors to trustees are positively and significantly associated with the latter's degree of religiosity; this behavior is consistent with the existence of the "folk sociology" belief that religious individuals are more cooperative, generous, and trusting (Orbel et al. 1992).

Ruffle and Sosis (2007) posit that individuals engage in costly religious rituals as a means to promote trust and cooperation among members of the religious sect (i.e., "in-group" cooperation). These authors recruited subjects from both secular and religious Israeli kibbutzim and then conducted several two-person common pool experiments. Overall, Orthodox males who go to synagogue daily make significantly smaller claims on the common pool than either Orthodox females or non-Orthodox subjects. Because women do not play as prominent a role in Orthodox rituals as males, Ruffle and Sosis interpret their findings as evidence that religious ritual does facilitate in-group cooperation. However, these results are also consistent with the claim that religiosity itself is associated with less selfish behavior. This is because the subjects in this experiment did not know the identity of their partners, so could not know whether they were cooperating within group or not.

The notion that religion fosters different behavior within group versus without also motivates the fourth study, Johansson-Stenman et al. (2005). These authors conduct two-person trust games using Hindu and Muslim subjects from rural Bangladesh. Neither Hindus nor 
Muslims exhibit preferential treatment to partners from their own group. However, this study does not explore differences in trust between religious and nonreligious subjects.

Aside from these four studies, there are a few studies that explore the effects of religion on other-regarding behavior in familiar experimental settings. Orbel et al. (1992) appear to be the first investigators to explicitly examine the behavior of religious versus non-religious subjects in a human subject experiment; they find that religion has no effect on contributions in a multi-person prisoners’ dilemma, although religious attendance among Mormons was correlated with cooperative behavior (half of the experiments in this study were conducted in Logan, Utah).

Eckel and Grossman (2003 and 2004) conduct several dictator games in which subjects unilaterally choose whether to give money to one of several listed secular charities. Eckel and Grossman find no significant difference in the propensity to make contributions between subjects who do or do not attend religious services regularly, although religious subjects are significantly more responsive when these donations to secular groups are subsidized. Tan (2006) also explores the effects of religion and specific religious beliefs (e.g., belief in God, belief in an afterlife, etc.) on German subjects behavior in dictator and ultimatum games; overall he concludes that religion has no effect on other-regarding behavior.

In short, what little is known about how religion influences behavior in common experimental games is somewhat mixed. Further, no previous studies on religion and cooperation and trust have utilized American subject in conventional public goods and trust games; in contrast, much of the empirical evidence discussed in the previous section is from American survey data. We examine how religious affiliation and attendance influences behavior among American experimental subjects in these canonical public goods and trust games. 
Finally, while the question of whether religious affiliation and participation are associated with contributions and trust is interesting in itself, this study also addresses a potential concern about the irreligious nature of the pool of subjects typically employed in economic experiments (i.e., college students). While many economists have previously been concerned about the composition of subject pools with regard to disproportionate exposure to economics instruction (e.g., Frey and Meier 2003 and 2005) or even liberal political ideology (Anderson, Mellor and Milyo 2005a), much less is known about the importance of religion and religiosity in determining laboratory behavior in public goods or trust games.

\section{Study Design}

In two previous studies, we generated data on voluntary contributions in a public goods experiment (Anderson, Mellor and Milyo 2008) and on trusting and trustworthy behavior in a bilateral trust experiment (Anderson, Mellor and Milyo 2006). These experiments shared in common many features, but most importantly identical surveys were administered to subjects in both sets experiments. The survey was composed of 42 questions on demographic characteristics, social and political attitudes, religious affiliation, and participation in religious services. In this study we analyze the data from these experiments in conjunction with the survey responses on religion.

The relevant survey questions for this study asked subjects to self-identify as Catholic, Protestant, Jewish, Muslim, some other religion, or no religion. ${ }^{8}$ In addition, we asked subjects how many times in a typical month they participated in organized religious services. These

${ }^{8}$ Because of the small number of subjects identifying themselves as either Jewish, Muslin or some other religion, we elected to pool these three responses into one category in our subsequent empirical analysis. 
questions are similar to those included in major opinion surveys, and so are consistent with how much of the previous social science literature measures both religion and religiosity.

We recruited 144 subjects from undergraduate classes at the College of William and Mary; each subject participated in the survey and either a public goods experiment or a trust experiment. The experimental sessions were conducted with groups of eight subjects; games were repeated for 30 rounds and feedback about others' decisions was provided at the end of each round. At the completion of each session, we randomly selected one round for the purpose of determining subjects' payments. In the public goods sessions, subjects earned an average of $\$ 19.57$; in the trust sessions, earnings averaged $\$ 22.21$. We administered the survey at the conclusion of the experiment, while subjects waited for their earnings to be calculated and distributed. $^{9}$

The public goods experiment follows the design introduced by Marwell and Ames (1979). Each person in a group of eight was given ten tokens to divide between a private account and a group account (i.e., the public good). The private account earned a return of $\$ 1$ to the individual, while each token contributed to the group account earned \$0.25 for all eight members of the group. Consequently, it is individually rational to contribute all tokens in the private account (since $\$ 1>\$ 0.25$ ), but socially inefficient to do so (since $8 * \$ 0.25=\$ 2>\$ 1$ ).

We also conducted 12 sessions of Berg, Dickhaut and McCabe’s (1995) investment game (a.k.a., the trust game). In this bilateral trust experiment, all subjects were endowed with \$10, and then randomly paired off, with half of the subjects designated as first movers, and their

${ }^{9}$ It is possible that survey responses are influenced by subjects' experiences in the experimental sessions; however, we know of no previous study that tests for the presence of order effects in the timing of the survey and experiment. 
partners designated as second movers. Within each pair, the first mover had the chance to pass some, all or none of their endowment to his anonymous partner. Any money passed was then tripled before being received by the second mover. Finally, the second mover was allowed to return to the first mover some, all or none of the money received. At the conclusion of each round of paired play, subjects were randomly re-assigned new partners (although the subjects remained in the role of first or second mover throughout the experiment). Consequently, it is straightforward to show using backward induction that the Nash equilibrium for this game is that no money will be passed in the first stage (since second movers have no incentive to return money in the second stage). ${ }^{10}$

The public goods and trust experiments share one other important feature; in some sessions of both experiments, we varied the fixed show-up payment given to subjects. This was done in order to induce heterogeneity among the subjects in these sessions; elsewhere, we analyze the effects of this induced inequality on contributions and trust (Anderson, Mellor and Milyo 2008 and 2006). The basic experimental design employed in both the public goods and trust experiments is described in Table 1. Each session was divided into three blocks of ten rounds. Each block represented a different distribution of fixed show-up payments, although the average fixed payment was $\$ 7.50$ in each block. ${ }^{11}$ Because of this aspect of the experiments, our subsequent regression analysis will control for the amount of the fixed payment received by each subject; in addition, we also test whether religion and religiosity have different effects in the

\footnotetext{
${ }^{10}$ This analysis applies to a one-shot game, but can also be extended to a finitely-repeated game with a certain endpoint.

${ }^{11}$ It is a standard practice to give subjects a fixed payment for showing up for an experiment. This payment supplements what subjects earn based on their decisions and serves as a lower bound on their compensation for participating in the experiment.
} 
sessions with induced inequality, versus the control sessions (in which all subjects were given the same show-up payment).

The variation in fixed payments to subjects is not purely accidental; this feature of the experiments allows us to test whether the association between religion and either public goods contributions or trust is conditioned on the artificially egalitarian environment of the experimental lab. A frequent concern with examining the effects of any sort of social conditioning on behavior in experiments is the possible influence of the laboratory setting itself. For example, religious teachings typically emphasize compassion to the less fortunate (e.g., the Parable of the Good Samaritan); for this reason, the potential influence of religion on behavior may not be manifest in a strictly egalitarian environment. Of course, financial constraints prohibit us from being able to make substantively large changes to subjects’ wealth; nevertheless, the induced heterogeneity employed here has been shown to influence subjects' behavior (see especially, Anderson, Mellor and Milyo 2008).

\section{Results}

We first present descriptive statistics and conduct non-parametric tests on the average play of each individual in our study (see Table 2). ${ }^{12}$ From the public goods experiment, we report mean values of the number of tokens contributed by subjects to the group account; we consider such contributions to reflect the value subjects place on the welfare of other subjects. From the trust experiments, we report mean amounts sent by first movers, a measure of the level of trust that player has in his or her randomly-matched partner. Finally, we also examine the

\footnotetext{
${ }^{12}$ Three subjects did not report information on their religious affiliation or participation; these subjects are dropped from our empirical analysis. One of these subjects participated in the public goods experiment, and two participated in the trust experiment (both were second movers).
} 
mean of the "return ratio" (the ratio of amount returned to amount available) among the second movers, which can be interpreted as the trustworthiness of these subjects. For each subject, we calculate the average decision over 30 rounds, and we then average those values over the subjects that participated in that feature of the experiment and provided sufficient responses to the survey. The means for the full sample are reported in Table 2, along with means by the subjects’ religious affiliation and participation in religious services.

The most striking finding from Table 2 is the absence of much variation in contributions, amount sent or amount returned by religious affiliation or participation. In fact, Mann-Whitney tests for each subgroup reveal no significant differences in group account contributions for any one group of subjects relative to the remaining subjects; likewise for the amount sent variable and the return ratio variable. Even so, the means listed in Table 2 do suggest some weak patterns in the data. For example, Catholics appear slightly less generous than Protestants, although this is not reflected in the return ratio. Also, there is some evidence of a gradient in voluntary contributions as participation in religious services increases, albeit this is only among subjects identifying a religious affiliation. Individuals reporting infrequent religious attendance actually contribute less than nonreligious individuals.

In contrast to the analysis above, we now conduct multivariate regression analysis of individual decisions as a function of individual characteristics and the experimental design. Because each block is associated with a particular distribution of fixed payments and consists of ten repetitions of the same game, we take as our unit of observation an individual's average actions within each block of ten games. Further, because this leaves us with three potentially 
non-independent observations per subject, we correct all of our estimated standard errors for clustering at the subject-level.

In Table 3, we report the results of ordinary least squares regressions, where the dependent variable is the average number of tokens contributed by an individual subject per tenround block. In each case, we control for subject's race, gender, and fixed payment amount; we also include controls for the order of the fixed payment treatment (egalitarian, skewed or symmetric), and whether the specific block was conducted with an unequal distribution or not. ${ }^{13}$ Finally, we examine several models that include indicators for any religious affiliation, type of religious affiliation, and self-reported frequency of attendance at religious services; none of these indicators is individually significant.

In Table 3, the indicators for religion are neither individually nor jointly significant. ${ }^{14}$ The estimated coefficient on Protestant affiliation is larger than for other denominations, but all of these estimated coefficients on religious affiliation are quite small relative to the mean contribution to the group account (which is 2.72). The indicators for attendance at religious services are also not individually significant. However, among subjects that attend religious services, we observe some evidence of a gradient in contributions associated with frequency of

\footnotetext{
${ }^{13}$ We did not observe any significant differences between the two inequality treatments, so we pool these observations and include only a single indicator variable for ease of exposition in subsequent tables.

${ }^{14}$ By pooling observations for individuals within each block of ten rounds, we have adopted a very conservative approach to dealing with the non-independence of multiple observations for each subjects. As an alternative, we have also estimated these models using each round of play as the unit of observation; this method gives us 30 observations per subject, so we also controlled for subject random effects and included indicators for each rounds. This alternative procedure had no substantive effect on our results. Consequently, we are more confident that the absence of a significant effect of religion on voluntary contributions is not an artifact of an overly strict correction for non-independent round-by-round observations.
} 
attendance. Further, the attendance indicators in Models 3 and 4 are jointly significant (at $p<.10$ and $\mathrm{p}<.05$, respectively). Using the estimates from Model 4 in Table 3, subjects who do not attend religious services (a group that includes both religious and nonreligious subjects) contribute about 0.8 more tokens than religious subjects that attend religious services once per month. This latter group also contributes about 1.7 fewer tokens than subjects with the highest rates of attendance.

Next, we conduct a similar analysis for the trust experiment. In Table 4, we report the results of identical models, except that the dependent variable is now the average number of tokens sent by the first mover. Once again, the religious affiliation indicators are neither individually nor jointly statistically significant, and there is little difference in behavior between Catholics and Protestants. However, in contrast to voluntary contributions, the estimated effects of religious affiliation are now consistently negative for the amount sent in the trust experiment. Regarding frequency of attendance at services, we no longer observe a gradient associated with attendance among religious subjects, nor are the attendance indicators individually or jointly significant. Nevertheless, it is striking that high-attendance religious subjects send about 2.5 fewer tokens on average compared to nonreligious subjects (see Model 3 in Table 4).

In Table 5, we describe our findings for the return ratio. As with amount sent, religious affiliation has a consistently negative, but insignificant effect; further, Catholics and Protestants behave in a very similar fashion. In addition, as was the case with voluntary contributions, nonreligious subjects return less than high-attenders, but more than individuals who attend services just once per month. However, the religious attendance indicators are not individually or jointly significant. Nevertheless, there is an interesting contrast between the amount sent and 
amount returned by subjects who frequently attend religious services: these subjects appear less trusting, but more willing to reciprocate.

Thus far, we have not found overwhelming evidence that either religion or religiosity is meaningfully related to behavior in public goods or trust games. If anything, our findings regarding voluntary contributions and trustworthiness suggest more of a difference among religious subjects based on rates of participation in services, than between religious and nonreligious subjects; however, regarding trust, we observe just the opposite. This is of course subject to the paucity of statistically significant differences, and our earlier caveat regarding the artificially egalitarian environment of the experimental lab.

As a check on whether the laboratory environment itself dampens the effects of religion and religiosity in these experiments, we now examine whether induced heterogeneity (through variation in the fixed show-up payment) reveals any significant differences in behavior. Accordingly, we reconsider the models above, but now interact the religion and attendance variables with an indicator for whether the fixed show-up payments were distributed equally or unequally. In order to streamline the presentation of these interacted results, we now simply distinguish between any religious affiliation and none, and we distinguish only between never attending service (the omitted category), attendance once per month, and attendance more than once per month.

Table 6 contains our results for this analysis of the group account contributions. The estimates from Model 1 demonstrate that the inequality treatment significantly reduces average contributions (as in Anderson, Mellor and Milyo 2004), even when controlling for religion and religiosity of subjects. However, the interacted effects of inequality and religion or religiosity 
are neither individually nor jointly significant (see Models 2 and 3 in Table 6). Even so, the findings from Models 2 and 3 indicate that once we interact religion and religiosity with the inequality indicator, the effect of inequality itself is mitigated. This suggests that the observed inequality effect in Model 1 is being driven in part by differences in behavior among religious subjects. And counter to our earlier intuition, the interaction of inequality and religion (or religiosity) is negatively associated with contributions. In particular, Model 3 indicates that lowattending subjects contribute about 0.6 fewer tokens in the inequality treatment; further, the attendance indicators in Model 3 are jointly significant $(\mathrm{p}<.05)$.

We also find evidence that both trusting and trustworthy behaviors are sensitive to the inequality treatment by religiosity. For tokens sent by the first movers (Table 7), we find only one significant effect of inequality: more frequent attendance is associated with significantly fewer tokens sent in the inequality treatment (see Model 3 in Table 7). The observed effect is also substantively large, as it is approximately $25 \%$ of the mean amount of tokens sent. Finally, in Table 8, we examine the return ratio, which we characterize as trustworthy behavior. As before, we observe only one significant interaction, but this time it is for occasional attendance and inequality (see Model 3 in Table 8). In addition, the estimated coefficient for this interaction is also large; occasional attenders in the inequality treatment return about 33\% more tokens than the mean return ratio. High attenders also return a higher fraction in the inequality treatment, but this interaction is not significant. Nevertheless, we cannot reject the null hypothesis that these two attendance interactions have the same coefficient ( $\mathrm{p}>.30)$. Therefore, in the trust games we observe religious attendance having opposite effects on trust and trustworthiness within the inequality treatment. 


\section{Conclusion}

We find that self-identified religious affiliation is unrelated to behavior in either the public goods or trust games. However, religiosity, measured by attendance at services, shows some weak association with behavior in both games. This suggests that future experimental research on the importance of religion might benefit from employing a combination of measures of religion, including religious affiliation (as in Fehr et al. 2003), participation in religious services (as in Eckel and Grossman 2004) and adherence to specific religious beliefs (as in Tan 2006).

Overall, the experimental and survey evidence presented here provides at best mixed support for the claim that religiosity makes an individual more other-regarding. Among subjects attending religious services, voluntary contributions in the public goods game increased with frequency of attendance. In the trust games, religiosity was unrelated to behavior, except in the inequality treatment. However, within the inequality treatment, individuals with the highest attendance rates at religious services were both less trusting and more trustworthy. This sensitivity to induced inequality reinforces our concerns that the behavioral effects of religion and religiosity may be mitigated by the otherwise artificially egalitarian laboratory environment. It is also worth noting that the role of the second-mover in the trust experiment is similar to that of a subject in a dictator game. However, Eckel and Grossman (2004) found religious participation to be unrelated to behavior in the dictator game; this contrasts somewhat with our findings on religiosity and "trustworthiness." We conjecture that the contextual differences in the second-mover's role in the trust game (i.e. responding to the first mover) may be responsible for the observed differences in behavior compared to dictators in Eckel and Grossman's experiment 
(also, recall that the receiver in their experiments was a secular charity). Consequently, future experimental work on the importance of religion may need to incorporate framing, induced inequality or some other procedure (perhaps participation by older subjects) for the potential effects of religion and religiosity to be made manifest.

Another aspect of the bilateral trust experiment is that trusting behavior by first movers is different from reciprocation by second movers (i.e., "trustworthiness"). For example, we observe this in the differential effects of religiosity in the inequality treatment. Elsewhere, Glaeser et al. (2000) report that survey-based measures of trust are poor predictors of trusting behavior in an experiment, but do predict trustworthiness. Consequently, the seemingly contradictory effects of religiosity in trust games with induced inequality (i.e., reduced trust, but increased reciprocity) is not so surprising. This weak but differential effect of religiosity on trust and reciprocity, which is less consistent with the maxim "do onto others," than "an eye for an eye,” may warrant further investigation.

Finally, we note that while observational studies often find that religion is associated with more cooperative, generous and trusting behavior; in the abstract laboratory setting religion appears to have less effect on behavior. Why do religious individuals become more egoistic in the controlled environment? Perhaps the Devil made them do it; however, we posit that the differences in observed behavior and outcomes between religious and nonreligious people may have more to do with differences in unobserved confounders, such as social environment or circumstances, than differences in preferences. Once religious subjects are placed into a controlled environment like an experimental game, their behavior appears to be not consistently or dramatically more other-regarding than that of nonreligious persons. This finding also echoes 
that in Anderson et al. (2005) in which we observe that liberal political ideology, often popularly associated with other-regarding preferences, also has little effect on individual behavior in public goods or trust games. 


\section{References}

Alesina, Alberto, Reza Baqir and William Easterly. 1999. "Public Goods and Ethnic Divisions.” Quarterly Journal of Economics, 114 (4): 1243-1284.

Alesina, Alberto and Elianna La Ferrara. 2002. “Who Trusts Others?” Journal of Public Economics, 85(2): 207-34.

Alesina, Alberto and Eliana La Ferrara.. 2000. "Participation in Heterogeneous Communities." Quarterly Journal of Economics, 115 (3): 847-904

Anderson, Lisa R., Jennifer M. Mellor, and Jeffrey Milyo. 2004. "Social Capital and Contributions in a Public Goods Experiment.” American Economic Review, 94 (2): 373376.

Anderson, Lisa R., Jennifer M. Mellor, and Jeffrey Milyo. 2005. "Do Liberals Play Nice? The Effects of Political Party and Ideology in Public Goods and Trust Games," in Advances in Applied Microeconomics: Experimental and Behavioral Economics. John Morgan, Editor. (JAI Press: Stamford, Connecticut).

Anderson, Lisa R., Jennifer M. Mellor, and Jeffrey Milyo. 2006. “Induced Heterogeneity in Trust Experiments,” Experimental Economics, 9:223-235.

Anderson, Lisa R., Jennifer M. Mellor, and Jeffrey Milyo. 2008. "Inequality and Public Good Provision an Experimental Analysis,” Journal of Socio-Economics, 37(3):1010-1028.

Andreoni, James. 1995. "Warm-Glow versus Cold-Prickle: The Effects of Positive and Negative Framing on Cooperation in Experiments." Quarterly Journal of Economics, 110(1): 1-21.

Arruñada, Benito. 2004. “The Economic Effects of Christian Moralities,” Universitat Pompeu Fabra, Economics and Business Working Paper Series, Number743 (March).

Barro, Robert and Rachel M. McCleary. 2003. "Religion and Economic Growth,” American Sociological Review, 68(5): 760-781.

Berg, Joyce, John Dickhaut and Kevin McCabe. 1995. "Trust, Reciprocity, and Social History.” Games and Economic Behavior, 10: 122-142.

Brooks, Arthur C. 2003. “Religious Faith and Charitable Giving,” Policy Review, No. 121.

Brooks, Arthur, C. 2005. “Does Social Capital Make You Generous?” Social Science Quarterly, 86(1): 1-15. 
Charness, Gary and Matthew Rabin 2002. "Understanding Social Preferences with Simple Tests,” Quarterly Journal of Economics, 117(3): 817-869.

Eckel Catherine C. and Philip J. Grossman 2003. "Rebate versus Matching: Does How We Subsidize Charitable Contributions Matter?” Journal of Public Economics, 87: 681-701.

Eckel, Catherine C. and Philip J. Grossman 2004. "Giving to Secular Causes by the Religious and Nonreligious: An Experimental Test of the Responsiveness of giving to Subsidies," Nonprofit and Voluntary Sector Quarterly, 33(2): 271-289.

Fehr Ernst and Urs Fischbacher, 2002. "Why Social Preferences Matter - The Impact of Nonselfish Motives on Competition, Cooperation, and Incentives,” Economic Journal, 112: C1-C33.

Fehr, Ernst, and Urs Fischbacher, Bernhard von Rosenbladt, Jurgen Schupp, and Gert G. Wagner. 2003. “A Nation-Wide Laboratory: Examining Trust and Trustworthiness by Integrating Behavioral Experiments into Representative Surveys.” IZA Discussion Paper No. 715 (February 2003), Bonn, Germany.

Frey, Bruno S. and Stephan Meier. 2003. “Are Political Economists Selfish and Indoctrinated? Evidence from a Natural Experiment,” Economic Inquiry, 41(3): 448-462.

Frey, Bruno S. and Stephan Meier. 2005. “Selfish and Indoctrinated Economists?” European Journal of Law and Economics, 19(2)” 165-171.

Glaeser, Edward L., David I. Laibson, Jose A. Scheinkman, and Christine L. Soutter. 2000. "Measuring Trust.” Quarterly Journal of Economics, 115 (3): 811-846.

Goldin, C. And L. Katz. 1999. "Human Capital and Social Capital: The Rise of Secondary Schooling in America, 1910-1940,” Journal of Interdisciplinary History, 29:683-723.

Greer, Tammy, Mitchell Berman, Valerie Varan, Lori Bobrycki, and Sheree Watson 2005. "We are Religious People; We are Vengeful People,” Journal for the Scientific Study of Religion, 44(1): 45-57.

Guiso, Luigi, Paolo Sapienza and Luigi Zingales 2003. "People’s Opium? Religion and Economic Attitudes,” Journal of Monetary Economics, 50: 225-282.

Iannaccone, Laurence R. 1998. "Introduction to the Economics of Religion,” Journal of Economic Literature, 36: pp. 1465-1496.

Inglehart, R. 1999. “Trust, Well-being and Democracy,” in Democracy and Trust, Ed. By M. Warren. Cambridge University Press (New York, NY). 
Johansson-Stenman, Olof, Minhaj Mahmud, and Peter Martinsson. 2005. "Trust and Religion: Experimental Evidence from Bangladesh,” manuscript, Göteborg University (Göteborg, Sweden).

La Porte, R., F. Lopez-de-Silane, A. Shleifer, R. W. Vishny. 1997. " "Trust in Large Organizations,” American Economic Review, 87(2): 333-338.

Marwell, Gerald and Ruth Ames. 1979. "Experiments on the Provision of Public Goods I: Resources, Interest, Group Size and the Free-Rider Problem.” American Journal of Sociology, 84(6): 1335-60.

Mellor, J. and J. Milyo 2005. "State Social Capital and Individual Health Status,” Journal of Health Politics Policy and Law, 30(6): 1101-1130.

Oosterbeek, Hessel, Randolph Sloop and Gus van de Kuilen. 2004. "Cultural Differences in Ultimatum Game Experiments: Evidence from a Meta-Analysis," Experimental Economics, 7:171-188.

Orbel, J., M. Goldman, M. Mulford, and R. Dawes. 1992. "Religion, Context and Constraint Towards Strangers,” Rationality and Society, 4(3): 291-307.

Putnam, Robert. 1993. Making Democracy Work: Civic Traditions in Modern Italy. Princeton University Press (Princeton, NJ).

Putnam, Robert. 2000. Bowling Alone. Simon and Schuster (New York, New York).

Ruffle, Bradley J. And Richard H. Sosis. 2007. "Does It Pay to Pray? Evaluating the Economic Return to Religious Ritual,” B.E. Journal of Economic Analysis and Policy: Contributions, 7(1): Article 18.

Schwadel, Philip 2005. "Individual, Congregational and Denominational Effects on Church Members' Civic Participation,” Journal for the Scientific Study of Religion, 44(2): 159171.

Tan, Jonathan H.W. 2006. "Religion and Social Preferences: An Experimental Study." Economics Letters, 90: 60-67.

Tan, Jonathan H.W. and Claudia Vogel. (forthcoming). "Religion and Trust: An Experimental Study.” Journal of Economic Psychology.

Wallis, James. 2005. God's Politics. Harper Collins Publishers (San Francisco, CA).

Weber, Max. 1930. The Protestant Ethic and the Spirit of Capitalism. Translated by Talcott Parsons. Charles Scribner's Sons (New York). 
Welch, Michael R., David Sikkink, Eric Sartain and Carolyn Bond 2004. "Trust in God and Trust in Man: The Ambivalent Role of Religion in Shaping Dimensions of Social Trust," Journal for the Scientific Study of Religion, 43(3): 317-343. 
Table 1. Experimental Design

\begin{tabular}{cccccc}
\hline \hline Session & Experiment & $\begin{array}{c}\text { Block 1 } \\
(10 \text { rounds })\end{array}$ & $\begin{array}{c}\text { Block 2 } \\
(10 \text { rounds })\end{array}$ & $\begin{array}{c}\text { Block 3 } \\
(10 \text { rounds })\end{array}$ & $\begin{array}{c}\text { Number of } \\
\text { Subjects }\end{array}$ \\
\hline $1-2$ & Public Goods & Egalitarian & Skewed & Symmetric & 16 \\
38049 & Public Goods & Skewed & Symmetric & Egalitarian & 16 \\
$5-6$ & Public Goods & Symmetric & Egalitarian & Skewed & 16 \\
& & Total Subjects in the Public Goods Experiment & 48 \\
38177 & Trust & Egalitarian & Skewed & Symmetric & 32 \\
38304 & Trust & Skewed & Symmetric & Egalitarian & 32 \\
$15-18$ & Trust & Symmetric & Egalitarian & Skewed & 32 \\
& & \multicolumn{2}{c}{ Total Subjects in the Trust Experiment } & 96 \\
\hline \hline
\end{tabular}

Notes: Egalitarian show-up payments = (8@ \$7.50)

Skewed show-up payments=(1@ \$20,4@\$7, $3 @$ \$4)

Symmetric show-up payments= (3@ \$10, 2 @ \$7.50, 3 @ \$5) 
Table 2. Mean Subject Decisions in Public Goods and Trust Experiments

\begin{tabular}{|c|c|c|c|}
\hline & $\begin{array}{l}\text { Public Goods } \\
\text { Experiment }\end{array}$ & \multicolumn{2}{|c|}{ Trust Experiment } \\
\hline & $\begin{array}{l}\text { Mean Group Account } \\
\text { Contribution }\end{array}$ & $\begin{array}{l}\text { Mean Tokens Sent to } \\
\text { Second Mover }\end{array}$ & $\begin{array}{l}\text { Mean Ratio of } \\
\text { Tokens Returned to } \\
\text { First Mover to } \\
\text { Tokens Available }\end{array}$ \\
\hline All Subjects & $\begin{array}{c}2.72 \\
(1.58) \\
n=47\end{array}$ & $\begin{array}{c}4.97 \\
(2.60) \\
\mathrm{n}=48\end{array}$ & $\begin{array}{c}0.34 \\
(0.18) \\
n=46\end{array}$ \\
\hline Any Religious Affiliation & $\begin{array}{c}2.74 \\
(1.59) \\
n=35\end{array}$ & $\begin{array}{c}4.63 \\
(2.53) \\
n=36\end{array}$ & $\begin{array}{c}0.34 \\
(0.19) \\
n=35\end{array}$ \\
\hline Catholic & $\begin{array}{c}2.52 \\
(1.64) \\
n=13\end{array}$ & $\begin{array}{c}4.03 \\
(2.05) \\
n=8\end{array}$ & $\begin{array}{c}0.35 \\
(0.22) \\
n=9\end{array}$ \\
\hline Protestant & $\begin{array}{c}3.03 \\
(1.69) \\
n=16\end{array}$ & $\begin{array}{l}4.67 \\
(2.34) \\
n=20\end{array}$ & $\begin{array}{c}0.33 \\
(0.19) \\
n=13\end{array}$ \\
\hline Other & $\begin{array}{c}2.44 \\
(1.24) \\
n=6\end{array}$ & $\begin{array}{c}5.13 \\
(3.50) \\
n=8\end{array}$ & $\begin{array}{c}0.34 \\
(0.17) \\
n=13\end{array}$ \\
\hline $\begin{array}{l}\text { Attends services once a } \\
\text { month }\end{array}$ & $\begin{array}{c}2.01 \\
(1.47) \\
n=13\end{array}$ & $\begin{array}{c}4.67 \\
(2.20) \\
n=11\end{array}$ & $\begin{array}{c}0.35 \\
(0.17) \\
n=5\end{array}$ \\
\hline $\begin{array}{l}\text { Attends services two or } \\
\text { three times a month }\end{array}$ & $\begin{array}{c}3.12 \\
(1.00) \\
n=8\end{array}$ & $\begin{array}{c}5.18 \\
(1.88) \\
n=13\end{array}$ & $\begin{array}{c}0.33 \\
(0.16) \\
n=9\end{array}$ \\
\hline $\begin{array}{l}\text { Attends services four } \\
\text { times a month or more }\end{array}$ & $\begin{array}{c}3.28 \\
(1.65) \\
n=11\end{array}$ & $\begin{array}{c}3.70 \\
(3.30) \\
n=7\end{array}$ & $\begin{array}{c}0.35 \\
(0.14) \\
n=11\end{array}$ \\
\hline
\end{tabular}

Notes: Cell entries are the mean values of subject choices taken over 30 decision making periods in each experiment; standard errors are in parentheses. Three subjects did not complete the survey questions on religion and so are excluded from the analysis. 
Table 3. Effects of Religiosity on Group Account Contributions

\begin{tabular}{lcccc}
\hline \hline & Model 1 & Model 2 & Model 3 & Model 4 \\
\hline Any Religious Affiliation & 0.214 & & -0.020 & \\
& $(0.36)$ & & $(0.03)$ & \\
Catholic & & -0.058 & & -0.420 \\
& $(0.08)$ & & $(0.54)$ \\
Protestant & 0.428 & & 0.279 \\
& $(0.66)$ & & $(0.33)$ \\
Other & -0.021 & & -0.400 \\
& $(0.03)$ & & $(0.54)$ \\
Attends services once a & & -0.775 & -0.847 \\
month & & $(1.01)$ & $(1.04)$ \\
Attends services two or & & 0.393 & 0.407 \\
three times a month & & $(0.55)$ & $(0.56)$ \\
Attends services four times & & 0.793 & 0.848 \\
a month or more & & $(0.98)$ & $(1.00)$ \\
\hline \hline
\end{tabular}

Notes: The dependent variable is the mean contribution by an individual within each ten round block $(n=141)$; standard errors are corrected for clustering at the level of the individual. Coefficients from OLS estimation are reported, with absolute values of t-statistics in parentheses. All models include controls for race, gender, the fixed payment to the individual, unequal versus equal fixed payment distribution, and the order of blocks within the session. Statistical significance is indicated by: ${ }^{* * *}$ for the 0.01 level, ${ }^{* *}$ for the 0.05 level, and ${ }^{*}$ for the 0.10 level. 
Table 4. Effects of Religiosity on Amount Sent in Trust Experiments

\begin{tabular}{|c|c|c|c|c|}
\hline & Model 1 & Model 2 & Model 3 & Model 4 \\
\hline Any Religious Affiliation & $\begin{array}{l}-1.356 \\
(1.47)\end{array}$ & & $\begin{array}{l}-1.004 \\
(1.04)\end{array}$ & \\
\hline Catholic & & $\begin{array}{l}-1.762 \\
(1.47)\end{array}$ & & $\begin{array}{l}-1.588 \\
(1.44)\end{array}$ \\
\hline Protestant & & $\begin{array}{l}-1.414 \\
(1.45)\end{array}$ & & $\begin{array}{l}-0.993 \\
(0.93)\end{array}$ \\
\hline Other & & $\begin{array}{l}-0.846 \\
(0.62)\end{array}$ & & $\begin{array}{l}-0.493 \\
(0.34)\end{array}$ \\
\hline $\begin{array}{l}\text { Attends services once a } \\
\text { month }\end{array}$ & & & $\begin{array}{l}-0.504 \\
(0.53)\end{array}$ & $\begin{array}{l}-0.729 \\
(0.72)\end{array}$ \\
\hline $\begin{array}{l}\text { Attends services two or } \\
\text { three times a month }\end{array}$ & & & $\begin{array}{l}0.019 \\
(0.02)\end{array}$ & $\begin{array}{l}0.074 \\
(0.08)\end{array}$ \\
\hline $\begin{array}{l}\text { Attends services four times } \\
\text { a month or more }\end{array}$ & & & $\begin{array}{l}-1.491 \\
(1.08)\end{array}$ & $\begin{array}{l}-1.432 \\
(1.01)\end{array}$ \\
\hline
\end{tabular}

Notes: The dependent variable is the mean contribution by an individual within each ten round block $(n=144)$; standard errors are corrected for clustering at the level of the individual. Coefficients from OLS estimation are reported, with absolute values of t-statistics in parentheses. All models include controls for race, gender, the fixed payment to the individual, unequal versus equal fixed payment distribution, and the order of blocks within the session. Statistical significance is indicated by: ${ }^{* * *}$ for the 0.01 level, ${ }^{* *}$ for the 0.05 level, and ${ }^{*}$ for the 0.10 level. 
Table 5. Effects of Religiosity on Return Ratio in Trust Experiments

\begin{tabular}{|c|c|c|c|c|}
\hline & Model 1 & Model 2 & Model 3 & Model 4 \\
\hline Any Religious Affiliation & $\begin{array}{l}-0.031 \\
(0.53)\end{array}$ & & $\begin{array}{l}-0.043 \\
(0.66)\end{array}$ & \\
\hline Catholic & & $\begin{array}{l}-0.013 \\
(0.15)\end{array}$ & & $\begin{array}{l}-0.021 \\
(0.24)\end{array}$ \\
\hline Protestant & & $\begin{array}{l}-0.021 \\
(0.29)\end{array}$ & & $\begin{array}{l}-0.032 \\
(0.40)\end{array}$ \\
\hline Other & & $\begin{array}{l}-0.055 \\
(0.83)\end{array}$ & & $\begin{array}{l}-0.067 \\
(0.92)\end{array}$ \\
\hline $\begin{array}{l}\text { Attends services once a } \\
\text { month }\end{array}$ & & & $\begin{array}{l}-0.006 \\
(0.08)\end{array}$ & $\begin{array}{l}-0.019 \\
(0.22)\end{array}$ \\
\hline $\begin{array}{l}\text { Attends services two or } \\
\text { three times a month }\end{array}$ & & & $\begin{array}{l}0.021 \\
(0.30)\end{array}$ & $\begin{array}{l}0.019 \\
(0.27)\end{array}$ \\
\hline $\begin{array}{l}\text { Attends services four times } \\
\text { a month or more }\end{array}$ & & & $\begin{array}{r}0.054 \\
(0.77) \\
\end{array}$ & $\begin{array}{l}0.050 \\
(0.70)\end{array}$ \\
\hline
\end{tabular}

Notes: The dependent variable is the mean contribution by an individual within each ten round block $(n=138)$; standard errors are corrected for clustering at the level of the individual. Coefficients from OLS estimation are reported, with absolute values of t-statistics in parentheses. All models include controls for race, gender, amount sent, the fixed payment to the individual, unequal versus equal fixed payment distribution, and the order of blocks within the session. Statistical significance is indicated by: ${ }^{* * *}$ for the 0.01 level, ${ }^{* *}$ for the 0.05 level, and ${ }^{*}$ for the 0.10 level. 
Table 6. Effects of Inequality and Religiosity on Group Account Contributions

\begin{tabular}{lccc}
\hline \hline & Model 1 & Model 2 & Model 3 \\
\hline Inequality Treatment & $-0.440^{*}$ & -0.222 & -0.122 \\
& $(1.97)$ & $(0.50)$ & $(0.24)$ \\
Any Religious Affiliation & 0.013 & 0.208 & 0.143 \\
& $(0.02)$ & $(0.24)$ & $(0.18)$ \\
Attends services once a month & -0.786 & -0.786 & -0.385 \\
& $(1.03)$ & $(1.03)$ & $(0.43)$ \\
Attends services more than once & 0.599 & 0.599 & 0.609 \\
a month & $(0.86)$ & $(0.86)$ & $(0.83)$ \\
Any Religious Affiliation * & & -0.293 & -0.195 \\
Inequality & & $(0.56)$ & $(0.48)$ \\
Attends services once a month * & & & -0.605 \\
Inequality & & & $(1.11)$ \\
Attends services more than once & & & -0.012 \\
a month * Inequality & & & $(0.03)$ \\
\hline \hline
\end{tabular}

Notes: The dependent variable is the mean contribution by an individual within each ten round block $(n=141)$; standard errors are corrected for clustering at the level of the individual. Coefficients from OLS estimation are reported, with absolute values of t-statistics in parentheses. All models include controls for race, gender, the fixed payment to the individual, unequal versus equal fixed payment distribution, and the order of blocks within the session. Statistical significance is indicated by: ${ }^{* * *}$ for the 0.01 level, ${ }^{* *}$ for the 0.05 level, and * for the 0.10 level. 
Table 7. Effects of Inequality and Religiosity on Amount Sent in Trust Experiments

\begin{tabular}{lccc}
\hline \hline & Model 1 & Model 2 & Model 3 \\
\hline Inequality Treatment & -0.370 & 0.165 & 0.205 \\
& $(1.24)$ & $(0.48)$ & $(0.52)$ \\
Any Religious Affiliation & -1.110 & -0.639 & -1.033 \\
& $(1.17)$ & $(0.63)$ & $(0.99)$ \\
Attends services once a month & -0.474 & -0.473 & -0.586 \\
& $(0.50)$ & $(0.49)$ & $(0.54)$ \\
Attends services more than once & -0.477 & -0.476 & 0.361 \\
a month & $(0.52)$ & $(0.52)$ & $(0.34)$ \\
Any Religious Affiliation * & & -0.711 & -0.119 \\
Inequality & & $(1.31)$ & $(0.21)$ \\
Attends services once a month * & & & 0.168 \\
Inequality & & & $(0.26)$ \\
Attends services more than once & & & -1.257 \\
a month * Inequality & & & $(1.91)^{*}$ \\
\hline \hline
\end{tabular}

Notes: The dependent variable is the mean contribution by an individual within each ten round block $(n=144)$; standard errors are corrected for clustering at the level of the individual. Coefficients from OLS estimation are reported, with absolute values of t-statistics in parentheses. All models include controls for race, gender, the fixed payment to the individual, unequal versus equal fixed payment distribution, and the order of blocks within the session. Statistical significance is indicated by: ${ }^{* * *}$ for the 0.01 level, ${ }^{* *}$ for the 0.05 level, and * for the 0.10 level. 
Table 8. Effects of Inequality and Religiosity on Return Ratio in Trust Experiments

\begin{tabular}{lccc}
\hline \hline & Model 1 & Model 2 & Model 3 \\
\hline Inequality Treatment & -0.011 & -0.010 & -0.030 \\
& $(0.08)$ & $(0.73)$ & $(1.74)^{*}$ \\
Any Religious Affiliation & -0.042 & -0.041 & -0.030 \\
& $(0.65)$ & $(0.59)$ & $(0.43)$ \\
Attends services once a month & -0.006 & -0.006 & -0.070 \\
& $(0.36)$ & $(0.07)$ & $(0.83)$ \\
Attends services more than once & 0.039 & 0.039 & 0.004 \\
a month & $(0.62)$ & $(0.62)$ & $(0.06)$ \\
Any Religious Affiliation * & & -0.001 & -0.018 \\
Inequality & & $(0.04)$ & $(0.66)$ \\
Attends services once a month * & & & 0.096 \\
Inequality & & & $(1.97)^{*}$ \\
Attends services more than once & & & 0.051 \\
a month * Inequality & & & $(1.21)$ \\
\hline \hline
\end{tabular}

Notes: The dependent variable is the mean contribution by an individual within each ten round block $(n=138)$; standard errors are corrected for clustering at the level of the individual. Coefficients from OLS estimation are reported, with absolute values of t-statistics in parentheses. All models include controls for race, gender, amount sent, the fixed payment to the individual, unequal versus equal fixed payment distribution, and the order of blocks within the session. Statistical significance is indicated by: ${ }^{* * *}$ for the 0.01 level, ${ }^{* *}$ for the 0.05 level, and ${ }^{*}$ for the 0.10 level. 